\title{
Interleukin-6 -174 G/C promoter polymorphism and nasal polyposis*
}

\author{
Eduardo Macoto Kosugi', Cíntia Meirelles de Camargo-Kosugi², Luc Louis \\ Maurice Weckx ${ }^{1}$, Ismael Dale Cotrim Guerreiro-da-Silva², Luiz Carlos Gregório ${ }^{1}$ \\ 1 Department of Otorhinolaryngology and Head and Neck Surgery of São Paulo Federal University \\ (UNIFESP-EPM), São Paulo, SP, Brazil \\ 2 Department of Ginecology of São Paulo Federal University (UNIFESP-EPM), São Paulo, SP, Brazil
}

\begin{tabular}{|c|c|}
\hline SUMMARY & $\begin{array}{l}\text { Introduction: Nasal polyposis is a chronic disease with unknown etiopathogenesis, although } \\
\text { inflammatory mechanisms seem to play a role. One of several inflammatory mediators linked } \\
\text { to nasal polyposis is Interleukin-6, which has a single nucleotide polymorphism -174 G/C that } \\
\text { seems to promote an inflammatory reaction. } \\
\text { Objective: To compare the prevalence of the - } 174 \text { G/C single nucleotide polymorphism between } \\
\text { a group of patients with nasal polyposis and a control group. } \\
\text { Method: Cross-sectional study with two groups (thirty two patients with nasal polyposis and } \\
\text { fifty five controls) to investigate the -174 G/C polymorphism in blood samples. Asthma, aspirin } \\
\text { intolerance and atopy were main exclusion criteria. IL-6 genotyping was performed using the } \\
\text { PCR method with forward primer 5'-ATGCCAAGTGCTGAGTCACTA-3' and reverse primer } \\
5 \text { '-GGAAAATCCCACATTTGATA-3', amplifying a } 226-b p \text { DNA fragment that contained the - } \\
\text { 174 position. The amplified fragment can be cleaved by restriction enzyme NlaIII when the-174 } \\
\text { position presented the C allele in two fragments of } 117 \text { and 109-bp, visualized by electrophore- } \\
\text { sis, classifying participants in GG, GC and CC. } \\
\text { Results: In the nasal polyposis group, 65.62\% of the patients had the GG genotype, while in the } \\
\text { control group only } 41.82 \% \text { had the GG genotype, a statistically significant difference, with an } \\
\text { odds ratio of } 2.65 \text {. } \\
\text { Conclusion: The -174 GG genotype was found more frequently in nasal polyposis patients than } \\
\text { in controls, when asthma, aspirin intolerance and atopy were excluded. } \\
\text { Key words: nasal polyps, interleukin-6, genetic polymorphism, restriction fragment length poly- } \\
\text { morphism, single nucleotide polymorphism }\end{array}$ \\
\hline
\end{tabular}

\section{INTRODUCTION}

Nasal polyposis (NP) is a chronic inflammatory disease of the nasal and paranasal sinus mucous membranes characterized by the formation of polyps, edematous masses of inflamed mucosa prolapsing into the nose ${ }^{(1)}$. It is also considered one of the subtypes of chronic rhinosinusitis (CRS), with polyp formation from the middle meatus ${ }^{(2)}$. Patients with NP typically present with nasal obstruction, rhinorrea, hyposmia and reduced quality of life ${ }^{(1-3)}$, but the diagnosis can only be confirmed by physical examination. Anterior rhinoscopy may not reveal small polyps restricted to the middle meatus, so nasal endoscopic examination is needed to definitively establish the diagnosis ${ }^{(2)}$. The surface of nasal polyps reveals frequent epithelial damage, a thickened basement membrane, and mostly oedematous to sometimes fibrotic stromal tissue, with a reduced number of vessels and glands but virtually no neuronal structure ${ }^{(4)}$. The cellular components of the polyps are eosinophils, mast cells, lymphocytes, neutrophils and plasma cells ${ }^{(1)}$.
NP does not seem to represent a single pathophysiological entity, but rather arises from a spectrum of mechanisms ${ }^{(1,3)}$. Although the exact pathogenesis of NP is still unknown, chronic inflammation appears to be the common pathway that culminates in polyp formation, since the polyp stroma contains numerous mediators, including cytokines, chemokines, growth factors and adhesion molecules ${ }^{(5,6)}$. Both Th1 and Th2 proinflammatory cytokines have been isolated in NP: interleukin (IL)-4, IL-5, IL-6, IL-8 and IL-13 ${ }^{(1,6)}$. Chemokines as RANTES and eotaxin, and growth factors as Transforming Growth Factor (TGF)- $\beta$ have also been isolated in NP ${ }^{(5)}$. Some of these mediators could promote chronic or recurrent inflammation that lead to polyp formation and growth ${ }^{(5,6)}$. Rapid ECM remodeling is necessary to support polyp proliferation. Although this has been widely accepted, regulatory mechanisms accounting for ECM remodeling in NP are still not clearly understood ${ }^{(7)}$. Among the inflammatory cells, activated 
eosinophils, usually located around vessels and glands, are a preeminent characteristic in about $80 \%$ of patients with $\mathrm{NP}^{(4)}$. The oedematous nature of nasal polyps consists of fibroblasts and infiltrating inflammatory cells localized around pseudocyst formations, which contain albumin and other plasma proteins, and supported by the subepithelial eosinophilic inflammation (4). Myofibroblasts, an activated phenotype of fibroblasts, could be responsible for ECM accumulation, polyp formation and recurrence in NP. They are rare in normal nasal mucosa, but much more frequent in nasal polyps, especially in association with asthma ${ }^{(4,7)}$.

IL-6 is a multifunctional proinflammatory cytokine produced by many different cells, including leukocytes, adipocytes, endothelial cells, fibroblasts and myocytes. It has been related to immune and inflammatory responses regulation and hepatic acute-phase protein synthesis. IL- 6 regulates production of adhesion molecules and induces secretion of monocyte chemotactic protein, an important mediator of release of other cytokines, such as TNF- $\beta$ and IL-1 that subsequently amplify the inflammatory reaction ${ }^{(8,9)}$. Payne et al., using microarray analysis, showed up-regulation of various innate immunity genes in NP, including IL-6 ${ }^{(10)}$. They showed increased IL-6 expression in NP tissues too ${ }^{(10)}$. Park et al. detected increased expression of IL-6 in cultured NP tissues ${ }^{(11)}$. Xu et al. demonstrated that Staphylococcal enterotoxin B (SEB) stimulation was able to increase various pro-inflammatory factors, including IL-6, in cultured nasal polyps, and then skewing the balance among $\mathrm{T}$ cell subsets by inhibiting Treg activity. So IL-6 could play a central role in suppressing Treg activity in NP. After blocking IL-6 in NP cultures, the authors found an increase in Treg activity ${ }^{(12)}$.

Fishman et al. have described a single-nucleotide polymorphism (SNP) at position -174 in the promoter region of the IL-6 gene ${ }^{(13)}$. Since it's description, this polymorphism has been found to be associated with the prevalence, incidence and/or prognosis of a variety of diseases, including Epstein-Barr virusassociated gastric carcinoma, Alzheimer's disease, rheumatoid arthritis, severe sepsis after trauma, atherosclerosis, ischemic stroke, abdominal aortic aneurysm, non-insulin-dependent diabetes mellitus, osteoporosis and systemic-onset juvenile chronic arthritis ${ }^{(8)}$. Basically, position -174 is occupied by guanosine $(\mathrm{G})$ or cytosine $(\mathrm{C})$ and this variability could be functional, because it modifies transcriptional regulation and cytokine levels, thereby leading to an inflammatory phenotype ${ }^{(13)}$.

Postulating that IL-6 could be related to NP, and that IL-6 -174 G/C SNP could modify the inflammatory response, we designed this study to compare $-174 \mathrm{G} / \mathrm{C}$ SNP frequencies in patients with and without NP. We couldn't find any literature studies investigating a relationship between this SNP and NP.

\section{MATERIALS AND METHODS \\ Study population}

The study population was formed by thirty-two volunteer patients with clinical and radiological diagnosis of nasal polyposis, while controls were fifty five healthy volunteers without symptoms or signs of CRS or NP. All participants underwent an otorhinolaryngological assessment including nasal endoscopy and skin prick-test for allergies. Only NP patients underwent CT-scans. For NP diagnosis, we considered the presence of polyps in both middle meati at the nasal endoscopic examination, confirmed on CT-scans. Nasal endoscopy resulted in the following semi-quantitative scores for polyps: 0absence of polyps; 1- polyps in middle meatus only; 2- polyps beyond middle meatus, but not blocking the nose completely; and 3- polyps completely obstructing the nose ${ }^{(2)}$. Controls did neither have symptoms of CRS/NP nor any kind of nasal polyp or nasal discharge at endoscopic exam.

Exclusion criteria included age below 18 years, medical history or symptoms suggesting asthma, salicylic acid intolerance, cystic fibrosis or ciliary dyskinesia, presence of nasal neoplasia, and one or more positives in a skin prick-test. The skin pricktest was performed with 10 known extracts: saline solution (negative control), histamine (positive control), Felis domesticus, Aspergillus fumigatus, Canis familiaris, Periplaneta americana, Penicillium notatum, D. pteronyssinus, Blomia tropicalis and Alternaria alternata. A wheel $3 \mathrm{~mm}$ larger than the negative control was considered a positive response.

\section{Study design}

This study was approved by the university's ethics committee under protocol number CEP 0501/06. All subjects signed informed consent for participation in the study.

This is a cross-sectional study with two groups: one was formed by patients with clinical and radiological diagnosis of nasal polyposis, so called NP Group, and the other was formed by healthy volunteers without any symptoms or signs of CRS/NP, so called Control Group. After inclusion and exclusion criteria had been observed, venous blood samples from all participants were collected for genomic DNA extraction. DNA was extracted, amplified by polymerase chain reaction, digested by restriction enzyme NlaIII and separated by electrophoresis, revealing the specific genotypes. All participants were classified in $-174 \mathrm{GG},-174 \mathrm{GC}$ or $-174 \mathrm{CC}$ genotype and statistical analysis was performed to compare both groups.

\section{DNA genotyping}

Genomic DNA from all participants was extracted from venous blood samples collected at São Paulo Hospital of São Paulo Federal University using a commercial extraction kit (Amersham Biosciences, Buckinghamshire, UK ${ }^{(8)}$ ). IL-6 genotyping was performed as describe by Fishman et al. ${ }^{(13)}$ using the polymerase chain reaction - based restriction fragment length polymorphism (PCR - RFLP) method with the forward primer: 5'-ATGCCAAGTGCTGAGTCACTA-3' and reverse 
primer: 5'-GGAAAATCCCACATTTGATA-3'. After initial denaturation at $94^{\circ} \mathrm{C}$ for $5 \mathrm{~min}, 40$ cycles of PCR were performed for $30 \mathrm{~s}$ at $94^{\circ} \mathrm{C}, 45 \mathrm{~s}$ at $52.8^{\circ} \mathrm{C}$, and $1 \mathrm{~min}$ at $72^{\circ} \mathrm{C}$, with a final extension at $72^{\circ} \mathrm{C}$ for $7 \mathrm{~min}$. These steps amplified a 226-bp DNA fragment that contained the -174 position. Then, $8 \mu \mathrm{l}$ of PCR product was digested with NlaIII (New England Biolabs Inc., Beverly, MA) for $4 \mathrm{~h}$ at $37^{\circ} \mathrm{C}$. When the -174 position had the $\mathrm{C}$ allele, the 226-bp PCR product was cleaved by restriction enzyme NlaIII into two fragments of 117 and 109bp. When the $\mathrm{G}$ allele was presented, the 226-bp fragment was not cleaved. Digestion products were separated by electrophoresis in 2\% agarose gel (Invitrogen Life Technologies, Carlsbad, CA) and visualized with ethidium bromide. Participants were classified in GG (where only the 226-bp fragments were visualized), GC (where 226, 117 and 109-bp fragments were visualized) and CC (where 117 and 109-bp fragments were visualized), as seen in Figure 1.

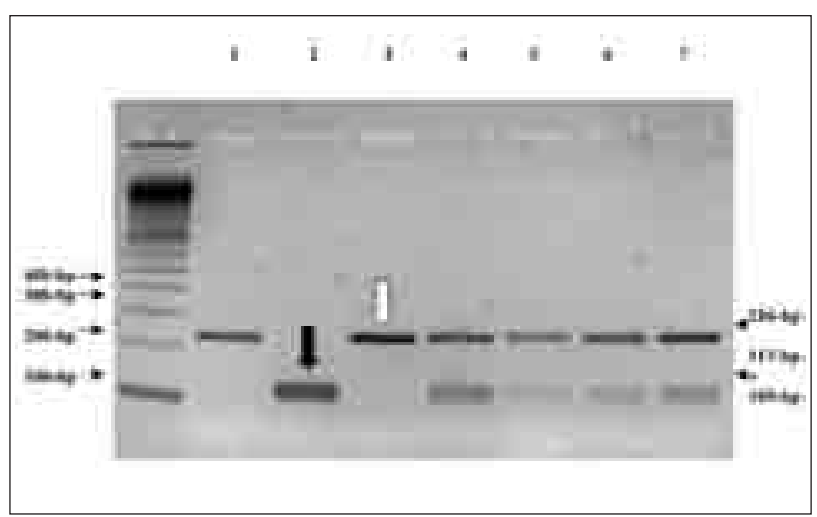

Figure 1. Agarose Gel Electrophoresis.

When the 226-bp DNA fragment contains a $\mathrm{G}$ at the -174 position, NlaIII doesn't cleave it (white arrow). In the presence of a $\mathrm{C}$ at the 174 position, NlaIII cleaves it into two fragments of 117 and 109-bp (black arrow). This agarose gel electrophoresis shows the following genotypes: 1-GG, 2-CC, 3-GG, 4-GC, 5-GC, 6-GC and 7-GC.

\section{Statistical analysis}

Age distributions in both groups were analyzed by Kolmogorov-Smirnov test to assess normality of data distribution. Then, sex and age homogeneity between groups were assessed by chi-squared test and student's t-test, respectively. The Hardy-Weinberg equilibrium analysis was performed using $\mathrm{p} 2+2 \mathrm{pq}+\mathrm{q} 2$ to estimate expected genotype distribution of $\mathrm{GG}, \mathrm{GC}$ and $\mathrm{CC}$, where $\mathrm{p}$ was the $\mathrm{G}$ allele frequency and $\mathrm{q}$ was the $\mathrm{C}$ allele frequency. These values were compared to observed genotype frequencies using the chi-squared test. Finally, genotype and allele distribution in both groups were compared using the chi-squared test. The odds ratio with a $95 \%$ confidence interval was calculated. For all tests, the p-values of 0.05 were considered significant.

\section{RESULTS}

Eighty-seven subjects were included: 55 in the control group and 32 in NP the group. Age had a normal distribution in both groups ( $p=0.29$ and $p=0.70$ in NP Group and Control Group, respectively). Both groups were homogeneous considering sex and age distribution $(p=0.85$ and $p=0.35$, respectively). Genotype frequencies of both groups were in HardyWeinberg equilibrium ( $\mathrm{p}=0.98$ and $\mathrm{p}=0.27$ in NP Group and Control Group, respectively). All participants' characteristics, including age, gender and genotype are shown in Table 1.

Table 1. Participants' characteristics.

\begin{tabular}{|c|c|c|c|c|c|}
\hline \multirow{2}{*}{$\overline{\text { Data }}$} & \multirow[b]{3}{*}{ (mean and SD) } & \multicolumn{4}{|c|}{ Groups } \\
\hline & & \multicolumn{2}{|c|}{$\begin{array}{c}\text { Nasal } \\
\text { polyposis }\end{array}$} & \multicolumn{2}{|c|}{ Control } \\
\hline Age - years & & 46.84 & 7.78 & 49.24 & 16.26 \\
\hline Gender - female & ( $\mathrm{N}$ and $\%)$ & 11 & 34.37 & 20 & 36.37 \\
\hline Polyp grade - right & (mean and SD) & 1.97 & 0.78 & - & - \\
\hline Polyp grade - left & (mean and SD) & 2.00 & 0.80 & - & - \\
\hline Previous NP surgery & $(\mathrm{N}$ and $\%)$ & 7 & 21.87 & - & - \\
\hline
\end{tabular}

$\mathrm{SD}=$ standard deviation; $\mathrm{N}=$ number; $\%=$ percentage

Nasal polyp grade according to the Lund-Kennedy system and previous NP surgeries were recorded as well.

Considering genotype distribution, the GG genotype was more common in the NP group, but there was no significant difference between groups when GG, GC and CC genotypes were compared. However, there was a significant difference between the groups when considering the GG and GC genotypes, as shown in Table 2. Considering the low frequency of the CC genotype in both groups and a high tendency of the GG genotype predominance in the NP group, we decided to combine the GC and CC genotypes in both groups, now called the nonGG genotype. When GG vs. non-GG genotypes were compared, we found a significant difference between NP and control groups, as presented in Table 3. The GG genotype was more common in the NP group with an odds ratio of 2.65 , sug-

Table 2. Genotype distribution.

\begin{tabular}{lcccc}
\hline \multicolumn{5}{c}{ Groups } \\
\hline Genotype & Nasal Polyposis & \multicolumn{2}{c}{ Control } \\
\hline GG & 21 & 65.62 & 23 & 41.82 \\
GC & 10 & 31.25 & 29 & 52.73 \\
CC & 1 & 3.13 & 3 & 5.45 \\
\hline Total & 32 & 100 & 55 & 100 \\
\hline
\end{tabular}

Chi-squared test: $\mathrm{GG}+\mathrm{GC} \mathrm{p}=0.037^{*}$

Table 3. Adjusted genotype distribution.

\begin{tabular}{lcccc}
\hline \multicolumn{4}{c}{ Groups } \\
\hline Genotype & Nusal Polyposis & \multicolumn{2}{c}{ Control } \\
\hline GG & 21 & 65.62 & 23 & 41.82 \\
Non-GG & 11 & 34.38 & 32 & 58.18 \\
\hline Total & 32 & 100 & 55 & 100 \\
\hline
\end{tabular}

Chi-squared test: GG + non-GG $\quad \mathrm{p}=0.032^{*}$

Odds Ratio $=2.6595 \%$ Confidence interval $=1.07$ a 6.56 
gesting that subjects with the GG genotype have higher risk of developing nasal polyposis.

Despite higher frequency of the G allele in the NP group (NP Group: $\mathrm{G}$ allele $=81.25 \%$ and $\mathrm{C}$ allele $=18.75 \%$; Control Group: $\mathrm{G}$ allele $=68.18 \%$ and $\mathrm{C}$ allele $=31.82$ ), there was no significant difference between the two groups.

\section{DISCUSSION}

Fishman et al. ${ }^{(13)}$ have described a SNP at position -174 in the promoter region of the IL- 6 gene, where either a guanosine or cytosine could occur. They observed a lower frequency of the $\mathrm{CC}$ genotype in patients with systemic-onset juvenile chronic arthritis (S-JCA) than in controls. Also, they observed lower levels of IL-6 in healthy subjects with a $\mathrm{C}$ allele. When studying IL- 6 transfected HeLa cells, they observed higher expression of IL- 6 before and after stimulation with lypopolysaccharide or IL-1 when the G allele construct was present. They concluded that the CC genotype could protect against S-JCA, while the $\mathrm{G}$ allele seemed to have a proinflammatory status.

After Fishman's first report, several diseases were related to the $-174 \mathrm{G} / \mathrm{C}$ SNP ${ }^{(8)}$, but the allele/genotype responsible for the proinflammatory phenotype was not always the $\mathrm{G}$ allele or the GG genotype. Some diseases were related to G/GG, whereas others were related to $\mathrm{C} / \mathrm{CC}$. These contradictory results were explained by Terry et al ${ }^{(9)}$. Studying four polymorphic sites in the IL-6 gene in two different cell lines (HeLa and ECV304), they observed that the polymorphisms could really influence IL-6 transcription and that this influence varied according to the studied cell type. Each cell type may have different expression of essential transcription factors or underlying differences in transcriptional control that could lead to differential expression of IL-6. So, while in some cell types the $\mathrm{G}$ allele / GG genotype promote the proinflammatory phenotype, in others the $\mathrm{C}$ allele / $\mathrm{CC}$ genotype are responsible for it $^{(9)}$.

Classically, IL-6 has been known as a member of the triumvirate of cytokines that drives acute inflammatory responses (TNF- $\alpha$ and IL-1 complete the trio). However, today IL- 6 is considered to play a role in disease processes involving chronic inflammation ${ }^{(14)}$. Cellular transition from acute to chronic inflammation is orchestrated in part by IL- $6{ }^{(15)}$. Moreover, IL-6 (with TGF- $\beta$ ) acts in the intersection between differentiation of naive $\mathrm{T}$ cells to Th17 (activation) or to Treg (suppression). Presence of IL- 6 unbalances this system to the Th17 side, promoting increases in Th17 cells and deficits in Treg cells, that finally leads to a chronic inflammatory process (as seen in auto-immune diseases) ${ }^{(14,16)}$.

Although NP has an uncertain etiology, several authors agree that a chronic inflammatory process is the common pathway for development of NP ${ }^{(1,2,5,-7,17)}$. Eosinophilic chronic inflammation is strongly associated with $\mathrm{NP}^{(2)}$, but other immune cells, such as fibroblasts and mast cells, and many cytokines also seem to play a role in NP pathogenesis ${ }^{(1,5)}$, including IL- ${ }^{(1,7,6,17)}$, because of its induction of collagen formation by fibroblasts, contributing to ECM remodeling and leading to polyp formation and growth ${ }^{(7)}$. Furthermore, IL-6 induces secretion of monocyte chemotactic protein, which amplifies the inflammatory response by releasing TNF- $\beta$ and IL-1 ${ }^{(8)}$, two of NP's inflammatory mediators ${ }^{(1,5)}$

NP is related to several diseases, including asthma and salicylic acid intolerance ${ }^{(2)}$. Because these associations could represent several inflammatory pathways ${ }^{(7)}$, we decided to establish several criteria of exclusion, trying to restrict this SNP study to one inflammatory pathway.

Considering that the IL-6 -174G/C SNP has functional status, and considering that IL- 6 may play a role in NP pathogenesis, we suggest a possible influence of the IL-6 -174G/C SNP in polyp formation. IL-6, a proinflammatory cytokine, could acquire "more inflammatory" status depending on the IL-6 174G/C genotype, because, as discussed above, this SNP's influence varies according to cell-type studied. In our study, we observed a higher frequency of the GG genotype in NP patients. Adjusted odds ratio for the GG genotype was 2.65, suggesting that people carrying this genotype are at higher risk for the development of NP. Possibly, the C allele could protect against NP by decreasing the inflammatory status of the nasossinusal mucosa or the GG genotype leads to more inflammatory activity causing NP.

Other inflammatory cytokines and their receptors, as IL-1 $\alpha$, IL-1 $\beta$, IL-1ra and IL-4, already have had their genetic polymorphisms studied and related to NP ${ }^{(17-19)}$. Possibly, in addition to IL-6, these cytokines could promote "proinflammatory phenotypes" depending on the polymorphic genotype. Although NP pathogenesis remains incompletely understood, a chronic inflammatory process seems to be the common pathway, because several cytokines have already been related to NP. It is possible that the genetic polymorphisms of these cytokines could be responsible for increased inflammation, thus playing an important role in NP. We believe there is a new horizon to be elucidated in this disease that remains a challenge for otorhinolaryngologists.

Concluding, in an IL-6 -174G/C promoter polymorphism study, we observed that the frequency of the GG genotype was higher in NP patients than in controls when asthma, aspirin intolerance and atopy were excluded. We need to study the influence of the $-174 \mathrm{G} / \mathrm{C}$ genotype on IL-6 expression to assess if the GG genotype could really increase inflammation and play a role in NP etiopathogenesis.

\section{ACKNOWLEDGEMENTS}

We would like to express our thanks to Dr Lee Harker for his kind help correcting this paper. 


\section{REFERENCES}

1. Pawankar R. Nasal polyposis: an update. Cur Opin Allergy Clin Immunol 2003; 3: 1-6.

2. Fokkens W, Lund V, Mullol J, European Position Paper on Rhinosinusitis and Nasal Polyps group. European position paper on rhinosinusitis and nasal polyps 2007. Rhinol Suppl 2007; 20: 1136.

3. Rinia AB, Kostamo K, Ebbens FA, van Drunen CM, Fokkens WJ. Nasal polyposis: a cellular-based approach to answering questions. Allergy 2007; 62: 348-358.

4. Watelet JB, Van Zele T, Gjomarkaj M, et al. Tissue remodeling in upper airways: where is the link with lower airway remodeling? Allergy 2006; 61: 1249-1258.

5. Figueiredo CR, Silva IDGC, Weckx LLM. Inflamatory Genes in Nasal Polyposis. Curr Opin Otolaryngol Head Neck Surg 2008; 16 : 18-21.

6. Danielsen A, Tynning T, Brokstad KA, Olofsson J, Davidson A. Interleukin 5, IL6, IL12, IFN- $\gamma$, RANTES and Fractalkine in human nasal polyps, turbinate mucosa and serum. Eur Arch Otorhinolaryngol 2006; 263: 282-289.

7. Haruna S, Nakanishi M, Otori N, Moriyama H. Histopathological features of nasal polyps with asthma association: an immunohistochemical study. Am J Rhinol 2004; 18: 165-172.

8. Nogueira de Souza NC, Brenna SMF, Campos F, Syrjänen KJ, Baracat EC e Silva IDCG. Interleukin-6 polymorphisms and the risk of cervical cancer. Int J Gynecol Cancer 2006; 16: 1278-1282.

9. Terry CF, Loukaci V, Green FR. Cooperative Influence of Genetic Polymorphisms on Interleukin-6 Transcriptional Regulation. J Biol Chem 2000; 275(24): 18138-18144.

10. Payne SC, Han JK, Huyett P, Negri J, Kropf EZ, Borish L, et al Microarray analysis of distinct gene transcription profiles in noneosinophilic chronic sinusitis with nasal polyps. Am J Rhinol 2008; 22: 568-581.

11. Park SK, Jang WH, Yang YI. Expression of pro-angiogenic cytokines and their inhibition by dexamethasone in na ex vivo model of nasal polyps. Biochem Biophys Res Commun. 2009; 379: 255-260.

12. Xu G, Xia JH, Zhou H, Yu CZ, Zhang Y, Zuo KJ, et al. Interleukin-6 is essential for Saphylococcal exotoxin B - induced T regulatory cell insufficiency in nasal polyps. Clin Exp Allergy. 2009; 39: 829-837.
13. Fishman D, Faulds G, Jeffery R, et al. The Effect of Novel Polymorphisms in the Interleukin-6 Gene on IL-6 Transcription and Plasma IL-6 Levels, and an Association with Systemic-Onset Juvenile Chronic Arthritis. J Clin Invest 1998; 102(7): 1369-1376.

14. Naugler WE, Karin M. The wolf in sheep's clothing: the role of interleukin-6 in immunity, inflammation and cancer. Trends Mol Med 2008; 14 (3): 109-119.

15. Hurst SM, Wilkinson TS, McLoughlin RM, et al. IL-6 and its soluble receptor orchestrate a temporal switch in the patter of leukocyte recruitment seen during acute inflammation. Immunity 2001; 14 (6): 705-714.

16. Iwakura Y, Ishigame H. The IL-23/IL-17 axis in inflammation. J Clin Invest 2006; 116: 1218-1222.

17. Bradley DT, Kountakis SE. Role of Interleukins and Transforming Growth Factor- in Chronic Rhinosinusitis and Nasal Polyposis. Laryngoscope 2005; 115: 684-686.

18. Karjalainen J, Joke-Erkkilä VP, Hulkkonen J, et al. The IL1A genotype is associated with nasal polyposis in asthmatic adults. Allergy 2003; 58: 393-396.

19. Park SK, Heo KW, Jung H, Yea SS e Yang YII. Expression of ciclooxygenase-2 and 5-lipoxygenase in nasal polyps associated with interleukin-4 promoter polymorphism -590. Otolaryngol Head Neck Surg 2006; 135: 928-932.

Dr Eduardo Macoto Kosugi

Rua Prof. João de Oliveira Torres 416 Jd. Anália Franco, São Paulo - SP, Brasil, CEP 03337-010

Tel: +55-11-3671-5883

E-mail: edumacoto@uol.com.br 